\title{
Commentary: Is "concomitant" a bad word in atrial fibrillation?
}

\author{
Marc Gillinov, MD, and Edward G. Soltesz, MD, MPH
}

\author{
From the Department of Thoracic and Cardiovascular Surgery, Cleveland Clinic, Cleveland, Ohio. \\ Disclosures: Dr Gillinov serves as a consultant to AtriCure, Edwards Lifesciences, Medtronic, CryoLife, and Ab- \\ bott. Dr Soltesz serves as a consultant to AtriCure. \\ Received for publication Sept 26, 2018; accepted for publication Sept 27, 2018; available ahead of print Nov 1, \\ 2018. \\ Address for reprints: Marc Gillinov, MD, Department of Thoracic and Cardiovascular Surgery, Cleveland Clinic/ \\ Desk J4-1, 9500 Euclid Ave, Cleveland, OH 44195 (E-mail: gillinom@ccf.org). \\ J Thorac Cardiovasc Surg 2019;157:1517-8 \\ $0022-5223 / \$ 36.00$ \\ Copyright (c) 2018 by The American Association for Thoracic Surgery \\ https://doi.org/10.1016/j.jtcvs.2018.09.077
}

Studies are designed to answer questions. In this issue of the Journal, Ad and colleagues ${ }^{1}$ address the question, "Is the long-term safety and efficacy of the Cox maze procedure similar in patients with and without mitral valve disease?" The answer is yes. More on that important finding in a moment. Before getting to that, let's address a more fundamental question: Why don't surgeons perform the Cox maze procedure in patients with atrial fibrillation (AF)?

In current practice, no more than one half of cardiac surgical patients with AF receive a Cox maze procedure, and this figure is even lower in patients without mitral valve disease. ${ }^{2,3}$ Previously, surgeons could rely on the uncertainty associated with unanswered questions to justify their decision to withhold the Cox maze procedure from patients afflicted by AF. There were questions about effectiveness; these were answered by numerous studies demonstrating that application of the Cox maze procedure substantially increases the likelihood of return to sinus rhythm. ${ }^{4,5}$ Concerns regarding safety and prolonged pump times were addressed by the development of alternate energy sources and studies confirming their safe application. ${ }^{4,5}$ More recently, large observational studies suggest that the Cox maze procedure may be associated with improved short- and long-term survival. ${ }^{6,7} \mathrm{We}$ should not need any more evidence to spur us to change practice and treat cardiac surgical patients with AF. However, it appears that we do.

With fastidious application of a standard lesion set and meticulous follow-up, Ad and colleagues ${ }^{1}$ demonstrate that the Cox maze procedure works equally well in those with and without mitral valve disease. Opening the left and right atria and extending crossclamp and bypass times by 30 minutes or less freed the majority of patients form $\mathrm{AF}$ and caused no harm. Given this demonstration of safety and effectiveness, Ad and coauthors conclude that "Surgeons should base the decision to perform surgical ablation procedures on...the benefit to patients.' Isn't this the single most important consideration behind every surgical decision?

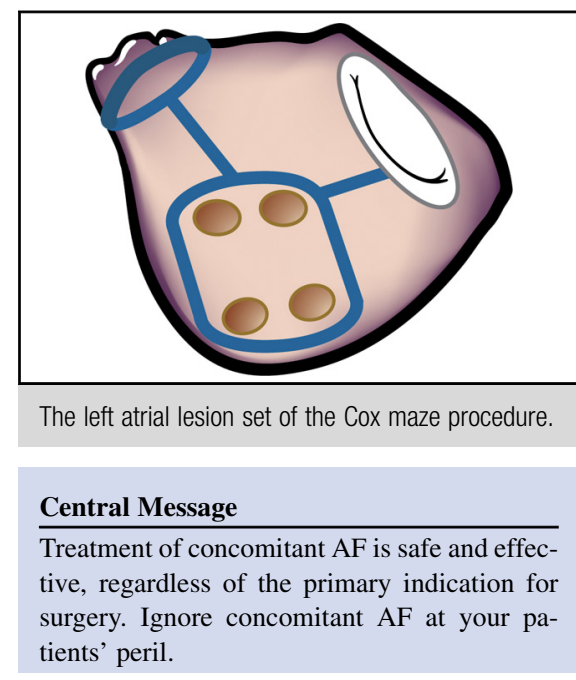

See Article page 1505 .

Returning to the original question, let's once more consider the faulty reasoning behind our underuse of a safe and effective therapy. Why do we leave AF untreated? I believe the answer lies in the word "concomitant." We hide behind this word, interpreting concomitant to mean "secondary" or "unimportant." Consider other scenarios that include patients with 2 cardiac problems. If we perform an aortic valve replacement (AVR) in a patient found to have a tight left anterior descending lesion, we accord the life-saving left internal mammary artery-left anterior descending graft the same importance as the life-saving AVR. If that patient with aortic stenosis has clean coronaries but long-standing persistent AF, most of us ignore the second condition (ie, AF) and perform AVR alone. We leave the patient with AF, meaning that we leave him or her with the requirement for life-long anticoagulation, an increased risk of stroke, and a reduced life expectancy. The decision to withhold the Cox maze procedure violates our primary directive; it harms the patient. Before choosing that course, ask yourself which operation you would want if you were the patient.

\section{References}

1. Ad N, Holmes SD, Rongione AJ, Badhwar V, Wei L, Fornaresio LM, et al. The long-term safety and efficacy of concomitant Cox maze procedures for atrial fibrillation in patients without mitral valve disease. J Thorac Cardiovasc Surg. 2019; 157:1505-14.

2. Ad N, Suri RM, Gammie JS, Sheng S, O'Brien SM, Henry L. Surgical ablation of atrial fibrillation trends and outcomes in North America. J Thorac Cardiovasc Surg. 2012;144:1051-60. 
3. Ad N, Henry L, Hunt S, Holmes SD. Impact of clinical presentation and surgeon experience on the decision to perform surgical ablation. Ann Thorac Surg. 2013;96:763-9.

4. Gillinov AM, Gelijns AC, Parides MK, DeRose JJ Jr, Moskowitz AJ, Voisine P, et al. Surgical ablation of atrial fibrillation during mitral valve surgery. $N$ Engl J Med. 2015;372:1399-409.

5. Philpott JM, Zemlin CW, Cox JL, Stirling M, Mack M, Hooker RL, et al. The ABLATE trial: safety and efficacy of Cox maze-IV using a bipolar radiofrequency ablation system. Ann Thorac Surg. 2015;100:1542-8.
6. Lee R, McCarthy PM, Wang EC, Vaduganathan M, Kruse J, Malaisrie SC, et al Midterm survival in patients treated for atrial fibrillation: a propensity-matched comparison to patients without a history of atrial fibrillation. J Thorac Cardiovasc Surg. 2012;143:1341-51.

7. Rankin JS, Grau-Sepulveda MV, Ad N, Damiano RJ, Gillinov AM, Brennan JM, et al. Associations between surgical ablation and operative mortality after mitral valve procedures. Ann Thorac Surg. 2018;105: 1790-6. 